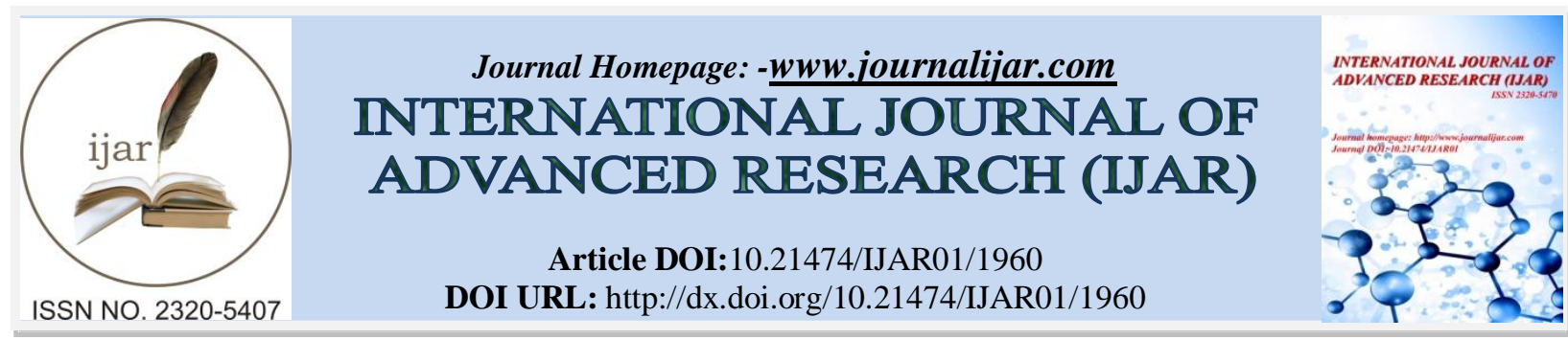

RESEARCH ARTICLE

\title{
THE INFLUENCE OF SMOKING METHOD ON THE LEVELS OF POLY CYCLIC AROMATIC HYDROCARBONS (PAHS) IN SMOKED CATFISH (CLARIASGARIEPINUS) FILLETS.
}

Adel A. El-Lahamy ${ }^{1,}$ Khalil I. Khalii ${ }^{2}$,Shaban A. El-Sherif ${ }^{1}$ and Awad A. Mahmud ${ }^{2}$.

1. National Institute of Oceanography and Fisheries, Fish Processing Technology Laboratory, Cairo, Egypt.

2. Food Science and Technology Department, Faculty of Agriculture,Fayoum University, Fayoum.

\section{Manuscript Info}

Manuscript History

Received: 12 August 2016

Final Accepted: 22 September 2016

Published: October 2016

Key words:-

Cat fish, Traditional smoking methods, PAHs.

\section{Abstract}

Fish smoking is among the oldest methods of preservation which mankind has used in fish processing. Potential health hazards associated with smoked fish may be caused by carcinogenic components as polycyclic aromatic hydrocarbons PAHs of wood smoke. In this study, catfish (Clariasgariepinus) fillets were subjected to traditional smoking method (cold and hot smoking). Polycyclic aromatic hydrocarbons PAHs of smoked fillets were determined using gas chromatography-mass spectrometry (GC-MS). Comparison of the concentration of PAHs in smoked fish samples processed by cold and hot smoking were investigated with the aim of determining the process that contributed more concentration of the PAHs to the fish samples.The detected low molecular weight PAHs in the cold and hot fish samples wereAcenaphthylene, Acenaphthene, Fluorene, Phenanthrene, Anthracene, Fluoranthene and Pyrene. Benzo(a)anthracene and Chrysene (PAH2)that high molecular weight probable consider human carcinogens were detected only in cold smoked samples. A higher concentrations $(\mathrm{P} \leq 0.05)$ of PAHs compoundswere found of cold smoked samples than hot smoked. The sum PAHs concentrations in the smoked fish fillets were $606.1 \mu \mathrm{g} / \mathrm{Kg}$ for cold smoked sample and $180.69 \mu \mathrm{g} / \mathrm{Kg}$ for hot smoked. Benzo[a]pyrene $(\mathrm{BaP})$ should be considered as indicators for carcinogenic PAHs in foods not detected in both hot and cold smoked fillets.PAH4 (benzo(a)pyrene, benz(a)anthracene, benzo (b)fluoranthene and chrysene); only benz(a)anthracene and chrysene were found in cold smoked samples $(10.7 \mu \mathrm{g} / \mathrm{kg})$ below than the maximum tolerable risk limits $(12 \mu \mathrm{g} / \mathrm{kg})$.Sum of toxic equivalency BaPeq (TEQ) was recorded high value $(1.722 \mu \mathrm{g} / \mathrm{kg})$ for cold smoked catfish fillets while, for hot smoked fillets was low value $(0.301 \mu \mathrm{g} / \mathrm{kg})$, these values of TEQ were below than maximum risk limit for BaPeq level $(2 \mu / \mathrm{kg})$ set by European Commission Regulation. Therefore, hot smoking method could be deemed safer than cold smokingfor human consumption, nevertheless both cold and hot smoking method not regarded as carcinogenic as reports recorded by European Commission Regulation and the results reveal that the

Corresponding Author:-Adel A. El-Lahamy. 
fish samples smoked by two different methods do not constitute a health risk, as the benzo (a) pyrene are not detected.

Copy Right, IJAR, 2016,. All rights reserved.

\section{Introduction:-}

Polycyclic aromatic hydrocarbons (PAHs) constitute a large class of organic compounds that are composed of two or more fused aromatic rings. They are primarily formed by incomplete combustion or pyrolysis of organic matter and during various industrial processes (EFSA, 2008). They are a large group of organic compounds that are included in the European Union (EU) and US Environmental Protection Agency (US EPA) priority pollutant list due to their mutagenic and carcinogenic properties (US EPA, 1994). More than 100 PAHs have been characterized in nature, 16 of which were classified by United States Environmental Protection Agency (USEPA) as found in (Table1) as priority pollutants. They include: naphthalene, acenaphthylene, benzo [b] fluoranthene, phenanthrene, dibenzo [a,h] anthracene, chrysene, benzo [a] pyrene, acenaphthene, benzo [k] fluoranthene, fluorene, pyrene, benzo [a] anthracene, anthracene, fluoranthene, indeno [1,2,3-cd] pyrene, and benzo [g,h,i] perylene (US EPA, 1993).

Table 1:- Names, chemical structure and molecular weight of some common PAHs.

\begin{tabular}{|c|c|c|c|c|}
\hline No & Name & Acronym & Structure & $\begin{array}{c}\text { Molecular } \\
\text { weight }\end{array}$ \\
\hline 1 & Naphthalene & Nap & & 128 \\
\hline 2 & Acenaphthylene & Acy & & 154 \\
\hline 3 & Acenaphthene & Ace & & 154 \\
\hline 4 & Fluorene & Flu & & 166 \\
\hline 5 & Phenanthrene & Phe & & 178 \\
\hline 6 & Anthracene & Anth & & 178 \\
\hline 7 & Fluoranthene & Flt & & 202 \\
\hline 8 & Pyrene & Pyr & & 202 \\
\hline 9 & Benzo (a) anthracene & $\mathrm{B}(\mathrm{a}) \mathrm{A}$ & $\pi^{2}$ & 228 \\
\hline 10 & Chrysene & Chr & $\mathbb{I}$ & 228 \\
\hline 11 & Benzo (b) Fluoranthene & $\mathrm{B}(\mathrm{b}) \mathrm{f}$ & & 252 \\
\hline 12 & Benzo (k) fluoranthene & $\mathrm{B}(\mathrm{k}) \mathrm{f}$ & & 252 \\
\hline 13 & Benzo (a) pyrene & $\mathrm{B}(\mathrm{a}) \mathrm{P}$ & $\pi \rightarrow 1=1$ & 252 \\
\hline 14 & Dibenzo $(a, h)$ anthracene & $\mathrm{DaA}$ & $\pi 5 x^{5}$ & 278 \\
\hline 15 & Benzo $(\mathrm{g}, \mathrm{h}, \mathrm{i})$ perylene & Bgp & $\pi{ }_{11}^{\pi}$ & 276 \\
\hline 16 & Indeno $(1,2,3, \mathrm{c})$ pyrene & Ip & "1" & 276 \\
\hline
\end{tabular}

Wenzl et al. (2006) recorded that PAHs containing up to four fused benzene rings are known as light PAHs and others containing more than four benzene rings are called heavy PAHs. Heavy PAHs are more stable and more toxic than light ones. Light PAHs are more volatile, water soluble, and less lipophilic than the heavy PAHs, so, PAHs migrate through the food chain into hydrophobic compartments and thus, accumulate in lipid components due to their lipophilic nature. Among PAHs, the benzo [a] pyrene $(\mathrm{BaP})$ concentration has received particular attention due to its higher contribution to overall burden of cancer in humans, being used as a marker for the occurrence and effect of carcinogenic PAHs in food (Rey et al., 2009). The benzo(a)pyrene has been recognized as carcinogenic for humans (WHO/IARC, 2012) and 6 other PAHs (benzo[a]anthracene, chrysene, benzo[b]fluoranthene, benzo[k] fluoranthene, dibenzo[a,h]anthracene and indeno[1,2,3-cd]pyrene) have been classified as probable human 
carcinogens (US EPA, 2002). Benzo [a] pyrene (BaP), the most carcinogenic PAH in soot, has for long been used as a marker for the occurrence and carcinogenicity of PAHs (Simko, 2002). The European Food Safety Authority (EFSA, 2008) concluded that BaP alone is not a suitable indicator for the occurrence and toxicity of PAHs in food and that eight specified PAHs (PAH8), for which oral carcinogenicity data are available, and/or a subgroup of these, PAH4 are more suitable markers.

Food can become contaminated by $\mathrm{PAH}_{\mathrm{S}}$ during thermal treatments that occur in processes of food preparation and manufacture (drying and smoking) and cooking (roasting, baking, and frying) (Ishizaki et al., 2010). Potential health hazards associated with smoked foods may be caused by carcinogenic components of wood smoke; mainly PAHs derivatives of PAHs, such as nitro-PAH or oxygenated PAH and to a lesser extent heterocyclic amines (Stołyhwo and Sikorski, 2005).

Food smoking belongs to one of the oldest technologies of food preservation which mankind has used in fish processing. Smoking has become a means of offering diversified high value added products as an additional marketing option for certain fish species where fresh consumption becomes limited (Gómez et al., 2009). The temperature of the smoke is in the range $25-45{ }^{\circ} \mathrm{C}$ during cold-smoking, in hot-smoking, the process may be carried out in different stages, during which the temperature of the smoke ranges from about $40-100^{\circ} \mathrm{C}$ and that in the center of the product may reach up to $85^{\circ} \mathrm{C}$ (Andrzej and Sikorski, 2005). Also, Gómez-Estaca et al. (2011) noticed that the traditional smoking techniques involve treating of pre salted whole or filleted fish with wood smoke from incomplete wood burning comes into direct contact with the product, this can lead to its contamination with PAHs if the process is not adequately controlled or if very intense smoking procedures are employed. Zelinkova and Wenzl (2015) reported that during smoking processes the substances with low molecular weight are primarily found in food and higher levels of these substances. However, it has to be stressed that these compounds have a lower toxicity profile compared to the high molecular weight members of the EPA PAHs list and hot smoking resulted in higher PAH levels than cold smoking.Garcia and Simal (2005) concluded that the actual levels of PAHs in smoked foods depend on several variables in the smoking process, type of smoke generator, combustion temperature, and degree of smoking.

Therefore, the current work is to investigate the effect of traditional smoking methods (cold and hot) on the levels of polycyclic aromatic hydrocarbons (PAHs) in smoked catfish fillets to select the best of smoking method has not hazard on human health.

\section{Materials and Methods:- \\ Fish Samples:-}

Fresh catfish Clariasgariepinus (1800-2300g weight, 56-60cm long) were obtained from Wadi EI-Ryan Lake, Fayoum Governorate, Egypt, during August 2015. The fish samples were transported in ice-box to the laboratory of fish processing technology, Shakshouk Research Station, National Institute of Oceanography and Fisheries (NIOF). Fish samples were prepared to smoking by beheaded, gutted and washed gently with tap water then skinned manually and filleted.

\section{Smoking Process:-}

Traditional cold and hot smoking was carried out of catfish fillets in smoking oven at Shakshouk Research Station (NIOF) as the following in Table 2 as reported by Abd El-Mageed (1994).

Table 2:- the conditions of smoking methods.

\begin{tabular}{|l|c|c|}
\hline Smoking conditions & cold smoking & hot smoking \\
\hline Brining & $10 \% \mathrm{NaCl}$ & $10 \% \mathrm{NaCl}$ \\
Brining period & $1 \mathrm{hr}$ & $3 \mathrm{hr}$ \\
\hline Air drying period & $3 \mathrm{hrs}$ & $50-90^{\circ} \mathrm{C}$ \\
\hline Temperature & $30-40^{\circ} \mathrm{C}$ & $5-6 \mathrm{hrs}$ \\
\hline Smoking period & $11-12 \mathrm{hrs}$ & sawdust \\
\hline The source of fuel & sawdust & \\
\hline
\end{tabular}




\section{Determination of Poly Cyclic Aromatic Hydrocarbons (PAHs):-}

PAHs were determined in Central Laboratory of Residue Analysis of Pesticides and Heavy Metals in Food (QCAP), Agricultural Research Centre. Cairo, Egypt.

\section{Chemicals and Reagents:-}

Acetone (Riedel-de $\mathrm{H}^{*}$ aen, purity 99.8\%), acetonitrile (Sigma-Aldrich, purity>99.9\%), toluene (Merck), dichloromethane chromatography grade, and n-hexane (purity >99.0\%) were the solvents used. Agilent QuEChERs salts and buffers were pre-packaged in anhydrous packages for EN 15662 containing $4 \mathrm{~g}$ magnesium sulfate (MgSO4), $1 \mathrm{~g}$ sodium chloride $(\mathrm{NaCl}), 1 \mathrm{~g}$ sodium citrate, and $0.5 \mathrm{~g}$ disodium citrate sesquihydrate. Silica gel (60120 mesh, Fluka) was activated at $150^{\circ} \mathrm{C}$ for 12 hours prior to use. A $1000 \mu \mathrm{g} / \mathrm{ml}$ stock solution of 14 PAHs includes naphthalene, fluorene, fluoranthene, benz(a)anthracene, chrysene, pyrene, benzo(b)fluoranthene, benzo(k)fluoranthene,benzo(a)pyrene, acenaphthene, phenanthrene, anthracene,acenaphthylene, and pyrene-d 10 (surrogate standard) and reference standards obtained from Sigma-Aldrich with purity $>95 \%$ were prepared, while benzo $(\mathrm{g}, \mathrm{h}, \mathrm{i})$ perylene and dibenz $(\mathrm{a}, \mathrm{h})$ anthracene were obtained as readymade of $100 \mu \mathrm{g} / \mathrm{ml}$ in methylene chloride and indeno[1,2,3-cd] pyrene $200 \mu \mathrm{g} / \mathrm{ml}$ in methanol. A $1 \mu \mathrm{g} / \mathrm{ml}$ working solution of all 16 PAHs was prepared in toluene. Calibration mixtures with concentration 2, 10, 50,100 and $500 \mathrm{ng} / \mathrm{ml}$ were prepared from serial dilution of the working solution in toluene where pyrene-d10 maintained at level $50 \mathrm{ng} / \mathrm{ml}$ in all calibration levels and all stored in refrigerator at $4^{\circ} \mathrm{C}$.

\section{Apparatus:-}

PFTE or polyethylene $50 \mathrm{~mL}$ tubes with screw cap and $15 \mathrm{~mL}$ tubes contain $1 \mathrm{~g}$ magnesium sulfate were obtained for sample extraction. Centrifuge up to $4000 \mathrm{rpm}$ (HeraeusLabofuge 400), Vortex, Automatic Pipettes (HirschmannLaborgerate) suitable for handling volumes of $10 \mu \mathrm{lto} 100 \mu \mathrm{l}$ and $100 \mu \mathrm{l}$ to $1000 \mu \mathrm{l}, 10 \mathrm{ml}$ solvent dispenser (HirschmannLaborgerate) for Acetonitrile. The glassware were washed with detergent and water then rinsedwith acetone and dried at $90^{\circ} \mathrm{C}$ before use.

\section{Sample Extraction Steps:-}

The validation procedure needs to be considered, the context of fitness for purpose and cost benefit criteria (Khorshid et al. 2015). About $10 \mathrm{~g}$ of fish sample was weighted in $50 \mathrm{ml}$ Teflon centrifuge tube, $50 \mu \mathrm{l} \mathrm{of} 10 \mu \mathrm{g} / \mathrm{ml}$ pyrened10 was added which acts as surrogate standard of $50 \mu \mathrm{g} / \mathrm{Kg}$, and each set of 6 replicates was spiked with 20 , 100 , and $500 \mu \mathrm{l}$ of $1 \mu \mathrm{g} / \mathrm{ml}$ spiking mixture to get 2,10 , and $50 \mu \mathrm{g} / \mathrm{kg}$, respectively. $10 \mathrm{ml}$ of acetonitrile was used for extraction, shaken for 2 minutes, mixed with Agilent QuEChERs, shaken for 1 minute, and centrifuged at $4000 \mathrm{rpm}$ for 5 minutes. Aliquots of the resulting supernatant were transferred to Teflon tube containing Mg So4, vortexed for 30 seconds, and centrifuged at $4000 \mathrm{rpm}$ for 2 minutes; $4 \mathrm{ml}$ of the acetonitrile layer was transferred into $50 \mathrm{ml}$ flask and then evaporated near to dryness.

\section{Clean up of PAHs:-}

Samples by Packed Solid Phase Extraction (SPE) Steps. All fish extracts were subjected to packed solid phase cleanup cartridge which was prepared in-house as follows. Plug a glass wool on $10 \mathrm{ml}$ length syringe; $1 \mathrm{~g} 20 \%$ deactivated silica gel and $0.2 \mathrm{MgSo}_{4}$ were weighted and conditioned with $5 \mathrm{ml}$ of $\mathrm{n}$-hexane/dichloromethane $(3: 2)$, the sample extract loaded to the cartridge using $10 \mathrm{ml}$ of elute (n-hexane/dichloromethane). Collect fractions in a 50 $\mathrm{mL}$ flask, evaporate on rotary evaporator at $40^{\circ} \mathrm{C}$ near to dryness and dissolve in $2 \mathrm{ml}$ toluene and then apply to GCMS for analysis.

\section{GC-MSD Conditions:-}

Agilent 6890N series gas chromatography instrument equipped with 5975 series mass selective detector and Agilent GC Column of model J\&W HP-5ms Ultra Inert with the specifications (30 m length, $0.25 \mathrm{~mm}$ internal diameter, $0.25 \mu \mathrm{m}$ film thickness) were used for both qualitative and quantitative determination of PAHs. Helium gas was used as the carrier gas; the column was maintained at a constant flow rate of $1.3 \mathrm{ml} / \mathrm{min}$. The back injector line was maintained at $260^{\circ} \mathrm{C}$. Injection volumes were $1.0 \mu \mathrm{l}$ in the splitless mode. The column temperature was initially held at $90^{\circ} \mathrm{C}$ for $2 \mathrm{~min}$, ramping to $180^{\circ} \mathrm{C}$ at a rate of $15^{\circ} \mathrm{C} / \mathrm{min}$, held at $180^{\circ} \mathrm{C}$ for $15 \mathrm{~min}$, ramping to $250^{\circ} \mathrm{C}$ ata rate of $10^{\circ} \mathrm{C} / \mathrm{min}$, held for $2 \mathrm{~min}$, ramping to $290^{\circ} \mathrm{C}$ at a rate of $10^{\circ} \mathrm{C} / \mathrm{min}$, and held for $10 \mathrm{~min}$. The mass spectrometer was operated in the ionization mode and spectra were acquired using a mass range of $45-450 \mathrm{~m} / \mathrm{z}$. Quality control and assurance of each patch were passed by monitoring the performance of the GCMS and the mass selective detector daily by tuning the mass detector and monitoring the sensitivity and linearity of the calibration curve, 
respectively, and also analyzing blank sample to confirm that there in contamination effect on the results during analysis.

\section{Statistical analysis:-}

The results were analyzed statistically using the least significant difference test (L.S.D) at $(P \leq 0.05)$ and Standard Deviation (Mean \pm SD) which calculated using SPSS 10.0 for windows (SPSS, 1991).

\section{Results and Discussion:-}

Polycyclic Aromatic Hydrocarbons (PAHs) in Smoked Catfish Fillets:-

Theresults in Table 3and figure1 were showed the polycyclic aromatic hydrocarbons (PAHs) concentrations of cold and hot smoked catfish samples $(\mu \mathrm{g} / \mathrm{kg}$ ). It could be found that 7 compounds of PAHs;acenaphthylene, acenaphthene, fluorene, phenanthrene, anthracene, fluoranthene and pyrene were detected in both cold and hot smoked fish samples, whilebenzo(a)anthracene and chrysene were detected only in cold smoked samples. Also, it could be noticed the high a significant difference $(\mathrm{P} \leq 0.05)$ between the concentrations of detected PAHscompoundsof cold and hot smoked catfish fillets. Where, higher $(\mathrm{P} \leq 0.05)$ PAHs compoundswere noticed of cold smoked samples than hot smoked.

The concentration of detected PAHs of cold and hot smoked samples were 105.8 and $36.3 \mu \mathrm{g} / \mathrm{Kg}$ acenaphthylene, 26.8 and 7.6 acenaphthene, 104.0 and 31.7 fluorene, 261.2 and 73.6 phenanthrene, 38.3 and 13.6 anthracene, 30.1 and 9.4 fluoranthene, 29.2 and 8.5 pyrene, respectively. Whilebenzo(a)anthracene and chrysene concentration were 7.5 and $3.2 \mu \mathrm{g} / \mathrm{Kg}$ of cold smoked fillets and not detected in hot smoked samples. Therefore, the total PAHs in the smoked fillets were 606.1 and $180.69 \mu \mathrm{g} / \mathrm{Kg}$ for the cold and hot smoked samples, respectively. Increasing the concentration of PAHs compounds in cold smoking is associated with increased duration of exposure to smoke a longer period than hot smoking. The variations of PAHs levels in cold and hot smoked samples due to the procedures used for smoking process; surface of fish exposed to the smoke, combustion temperature, smoking time, oxygen accessibility and density of smoke (Basak et al., 2010), while Zelinkova and Wenzl (2015) found that hot smoking resulted in higher PAH levels than cold smoking. These results of total PAHs concentrations were lower than results of Silva et al.(2011) who stated that the concentration of total PAHs in smoked cat fish (Arius heude loti), sole (Cynoglossussenegalensis) and haake used sawdust as a source of fuel were 2058.1, 1395.2 and 856.2 $\mu \mathrm{g} / \mathrm{kg}$ respectively.

Table 3:- polycyclic aromatic hydrocarbon (Mean $\pm \mathrm{SD}$ ) in smoked catfish fillets $(\mu \mathrm{g} / \mathrm{kg}$ sample).

\begin{tabular}{|c|l|r|r|c|}
\hline No. & PAHs & Cold & Hot & L. S. D. at 5\% \\
\hline 1 & Naphthalene & ND & ND & - \\
2 & Acenaphthylene & $105.8 \pm 1.160$ & $36.3 \pm 0.208$ & 0.08 \\
3 & Acenaphthene & $26.8 \pm 0.550$ & $7.6 \pm 0.032$ & 1.01 \\
4 & Fluorene & $104.0 \pm 1.527$ & $31.7 \pm 0.513$ & 0.00 \\
5 & Phenanthrene & $261.2 \pm 2.196$ & $73.6 \pm 0.346$ & 0.26 \\
6 & Anthracene & $38.3 \pm 0.404$ & $13.6 \pm 0.442$ & 0.50 \\
7 & Fluoranthene & $30.1 \pm 1.159$ & $9.4 \pm 0.346$ & 0.02 \\
8 & Pyrene & $29.2 \pm 1.039$ & $8.5 \pm 0.346$ & 0.31 \\
9 & Benzo(a)anthracene & $7.5 \pm 0.635$ & ND & 0.00 \\
10 & Chrysene & ND & ND & 0.00 \\
11 & Benzo(b)Fluoranthene & ND & ND & - \\
12 & Benzo(k)fluoranthene & ND & ND & - \\
13 & Benzo(a)pyrene & ND & ND & - \\
14 & Dibenzo(a,h)anthracene & ND & ND & - \\
15 & Benzo(g,h,i)perylene & ND & ND & - \\
16 & Indeno(1,2,3,c)pyrene & 606.1 & ND & - \\
& DPAHs & 10.7 & & \\
& DPAH4 & & & \\
\hline
\end{tabular}

ND: Not detected.

PAH4: The sum of benzo [a] anthracene, chrysene, benzo [b] fluoranthene and benzo [a] pyrene. 


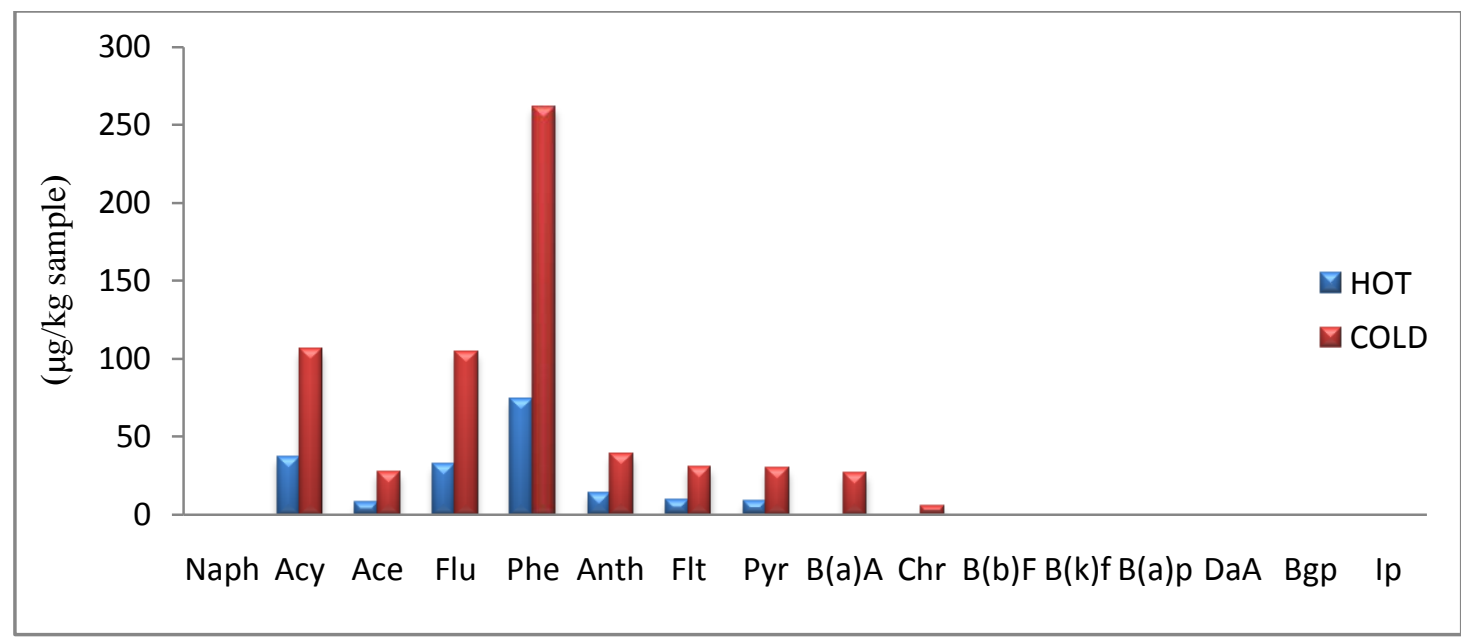

Fig 1:- levels of poly cyclic aromatic hydrocarbon PAHs detected in hot and cold smoked catfish fillets $(\mu \mathrm{g} / \mathrm{kg}$ sample).

From Table (3) and Fig. (1), we observed that, in cold smoked fillets; benzo (a) anthracene and chrysene (high molecular weight) recorded lower values than PAHs contain low molecular weight (acenaphthylene, acenaphthene, fluorene, phenanthrene, anthracene, fluoranthene and pyrene), while PAHs compounds that had higher molecular weight such as benzo(a)pyrene not detected. These results were similar with reported by (Gómez-Estaca et al., 2011) and Zelinkova and Wenzl (2015) found that the substances with low molecular weight are primarily found in food and have a lower toxicity profile compared to the high molecular weight members of the (EPA) PAHs list.

Also, it was found that PAHs; acenaphthylene, acenaphthene, fluorene, phenanthrene and anthracene which have two to three rings that found in cold and hot smoked samples are not regarded as carcinogenic, this confirmed by Neff (1985), he reported that the PAHs contains four, five and six rings appear to be more carcinogenic than PAHs with smaller or larger ring systems and highly angular configured rations tend to be more carcinogenic than linear ring systems.

Benzo(a)anthracene and chrysene compounds which found only in investigated cold smoked fish fillets probable consider human carcinogens as classification by US EPA (1994), which recorded that seven of the PAHs have been classified by the US EPA as compounds of probable human carcinogens, these are benzo(a)anthracene, benzo(b)fluoranthene, benzo(k)fluoranthene, chrysene, benzo(a)pyrene, dibenzo(a,h)anthracene, and indeno(1,2,3c)pyrene. These PAHs compounds not detected in hot smoked samples so, hot smoking method may be safer than cold smoking for human consumption.

\section{Carcinogenity Factors of PAHs:-}

Benzo(a)pyrene (BaP):-

Benzo[a]pyrene, should be considered as indicators so as to better assess both occurrence and carcinogenic PAHs in foods. In our study, $\mathrm{BaP}$ was not d detected in all smoked samples (hot or cold smoked fillets). Therefore, it is noteworthy that all the PAHs detected in these smoked fish samples are not carcinogenic. However, the limit permitted by European legislation (OJEU, 1881/2006) is $5 \mathrm{mg}$ of benzo(a)pyrene/kg of smoked fish. These results are in agreement with reported by Silva et al. (2011) and Olabemiwo et al. (2011), they reported that BaP was not detected in the smoked fish samples, while, contrary results were reported by Mihalca et al. (2011), who found that the Levels of benzo[a]pyrene of smokedrainbow trout andbrook trout fish were 8.4 and $0.4 \mu \mathrm{g} / \mathrm{kg}$, respectively.

\section{PAH4:-}

In this study, Table (3)and figure (1) clearly shows that four substances PAH4(benzo(a)pyrene, benz(a)anthracene, benzo (b)fluoranthene and chrysene) classified as probable human carcinogens (US EPA, 2002); only benz(a)anthraceneand chrysene were found in cold smoked fish samples in low sum concentrations $(10.7 \mu \mathrm{g} / \mathrm{kg})$ below than the maximum tolerable risk limits $(12 \mu \mathrm{g} / \mathrm{kg}$ ), set by European Commission Regulation (OJEU, 835/2011) for muscle meat of smoked fish and smoked fishery products, while not detected in hot smoked fillets. This variation in (PAH4) levels between hot and cold smoked fillets may be attributed to exposure of cold smoked 
fillets to smoke for a period longer than hot smoked fillets. These results are in agreement with reported by Ongwech et al. (2013), who reported that PAH4 concentrations in three smoked L. niloticus samples from three markets were $11.00,8.14$, and $10.98 \mu \mathrm{g} / \mathrm{kg}$, these values were below the harmful maximum level $(12 \mu \mathrm{g} / \mathrm{kg})$.

\section{Toxic Equivalency as A measure of Carcinogenicity of PAHs (BaPeq):-}

The carcinogenic potency of each PAH identified in the investigated samples was also determined in terms of $\mathrm{BaP}$ equivalent concentration, commonly referred to as the toxic equivalency (TEQ). A list of toxic equivalency factors (TEFs) recorded by Nisbet and La Goy (1992) in Table (4) that used for estimate the carcinogenic potency of total PAHs (that is, total BaP equivalent concentration) using the formula:

TEQ $(\mu \mathrm{g} / \mathrm{kg})=(\mathrm{PAH}(\mu \mathrm{g} / \mathrm{kg}) \times \mathrm{TEF})$

Where: TEQ is the toxic equivalency of the reference PAH compounds.

TEF: The toxic equivalent factor.

Table 4:- Toxic equivalency factors (TEF) for the 16 priority PAHs.

\begin{tabular}{|l|c|l|l|}
\hline PAH & TEF & PAH & TEF \\
\hline Naphthalene & 0.001 & Benzo(a)anthracene & 0.10 \\
Acenaphthylene & 0.001 & Chrysene & 0.01 \\
Acenaphthene & 0.001 & Benzo(b)Fluoranthene & 0.10 \\
Fluorene & 0.001 & Benzo(k)fluoranthene & 0.10 \\
Phenanthrene & 0.001 & Benzo(a)pyrene & 1.00 \\
Anthracene & 0.010 & Dibenzo(a,h)anthracene & 0.10 \\
Fluoranthene & 0.001 & Benzo(g,h,i)perylene & 1.00 \\
Pyrene & 0.001 & Indeno(1,2,3,c)pyrene & 0.01 \\
\hline
\end{tabular}

The computed BaPeq (TEQ) values for detected PAHs and identified in the smoked catfish fillets sampled are shown in Table (5). In cold smoke fish fillets, benzo(a)anthracene had the highest value of TEQ, while acenaphthene had the lowest value while, in hot smoked samples anthracene had the highest value of TEQ but Pyrene had the lowest value. The sum of toxic equivalency (TEQ) was recorded higher $(\mathrm{P} \leq 0.05)$ value $(1.722 \mu \mathrm{g} / \mathrm{kg})$ for cold smoked catfish fillets while, for hot smoked fillets was lower $(\mathrm{P} \leq 0.05)$ value $(0.301 \mu \mathrm{g} / \mathrm{kg})$. Nevertheless, these values of total toxic equivalency in bothcold and hot smoked fish fillets were below than maximum risk limit for BaPeq level $(2 \mu / \mathrm{kg})$ set by European Commission Regulation(OJEU, 835/2011). Also these values of total toxic equivalency were below than results that reported by Ongwech et al. (2013) who found that TEQ concentrations in three smoked L. niloticus samples from three markets were 3.860, 1.731 and $2.523 \mu \mathrm{g} / \mathrm{kg}$.

Table 5:- Toxic equivalency TEQ of detected PAHs in smoked catfish fillets $(\mu \mathrm{g} / \mathrm{kg})$.

\begin{tabular}{|l|c|c|c|}
\hline \multirow{2}{*}{ PAHs } & \multicolumn{2}{|c|}{ BaPeq of PAHs in smoked samples by; } & $\begin{array}{c}\text { L. S. D. at } \\
5 \%\end{array}$ \\
\cline { 2 - 4 } & Cold & Hot & \\
\hline Acenaphthylene & 0.106 & 0.036 & 0.05 \\
Acenaphthene & 0.027 & 0.008 & 0.01 \\
Fluorene & 0.104 & 0.032 & 0.02 \\
Phenanthrene & 0.261 & 0.074 & 0.02 \\
Anthracene & 0.383 & 0.137 & 0.09 \\
Fluoranthene & 0.030 & 0.009 & 0.01 \\
Pyrene & 0.029 & 0.005 & 0.01 \\
Benzo(a)anthracene & 0.750 & ND & 0.00 \\
Chrysene & 0.032 & ND & 0.00 \\
NTEQ & 1.722 & 0.301 & 0.09 \\
MRL & 2.000 & 2.000 & \\
\hline
\end{tabular}

N.D $=$ Not detected, BaPeq, $(T E Q)=$ Toxic equivalency, MRL: maximum risk limit for TEQ

In the same trend, the figures $(2,3)$ cleared that the TEQ for Benzo(a)anthracene $(B(a) A)$ in cold smoked fillets was recorded $(0.750 \mu \mathrm{g} / \mathrm{kg})$ about $43 \%$ of total BaPeq $(1.722 \mu \mathrm{g} / \mathrm{kg})$ while, in hot smoked fillets $(\mathrm{B}(\mathrm{a}) \mathrm{A})$ was not 
detected. Also, in hot smoked samples anthracene was recorded $(0.137 \mu \mathrm{g} / \mathrm{kg})$ about $45 \%$ of total $\mathrm{BaPeq}$ $(0.301 \mu \mathrm{g} / \mathrm{kg})$ and lower than that of cold smoked fillets. Thus, based on the use of benzo(a)pyrene, PAH4 and BaPeq as indicators for the carcinogenicity of PAHs, hot smoked catfish (Clariasgariepinus)fillets could be deemed safe for human consumption more than cold smoked samples.

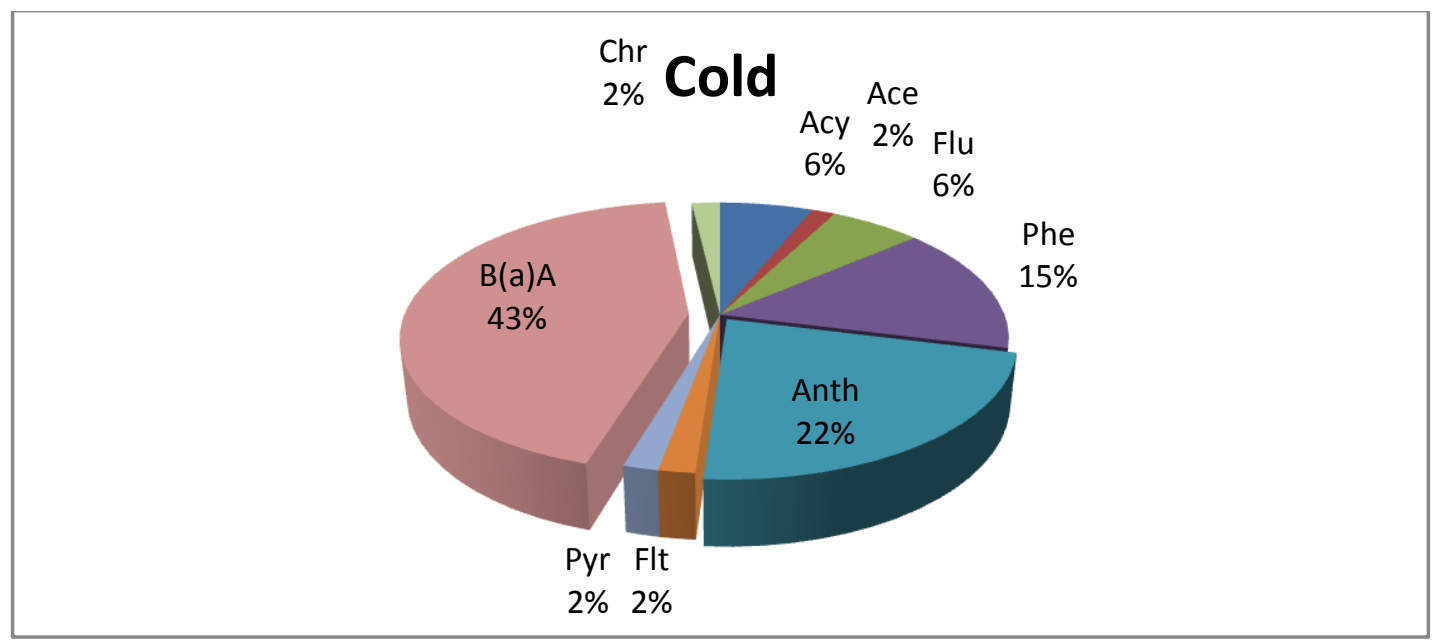

Figure 2:-Percent of detectedBaPeq PAHs in cold smoked catfish fillets.

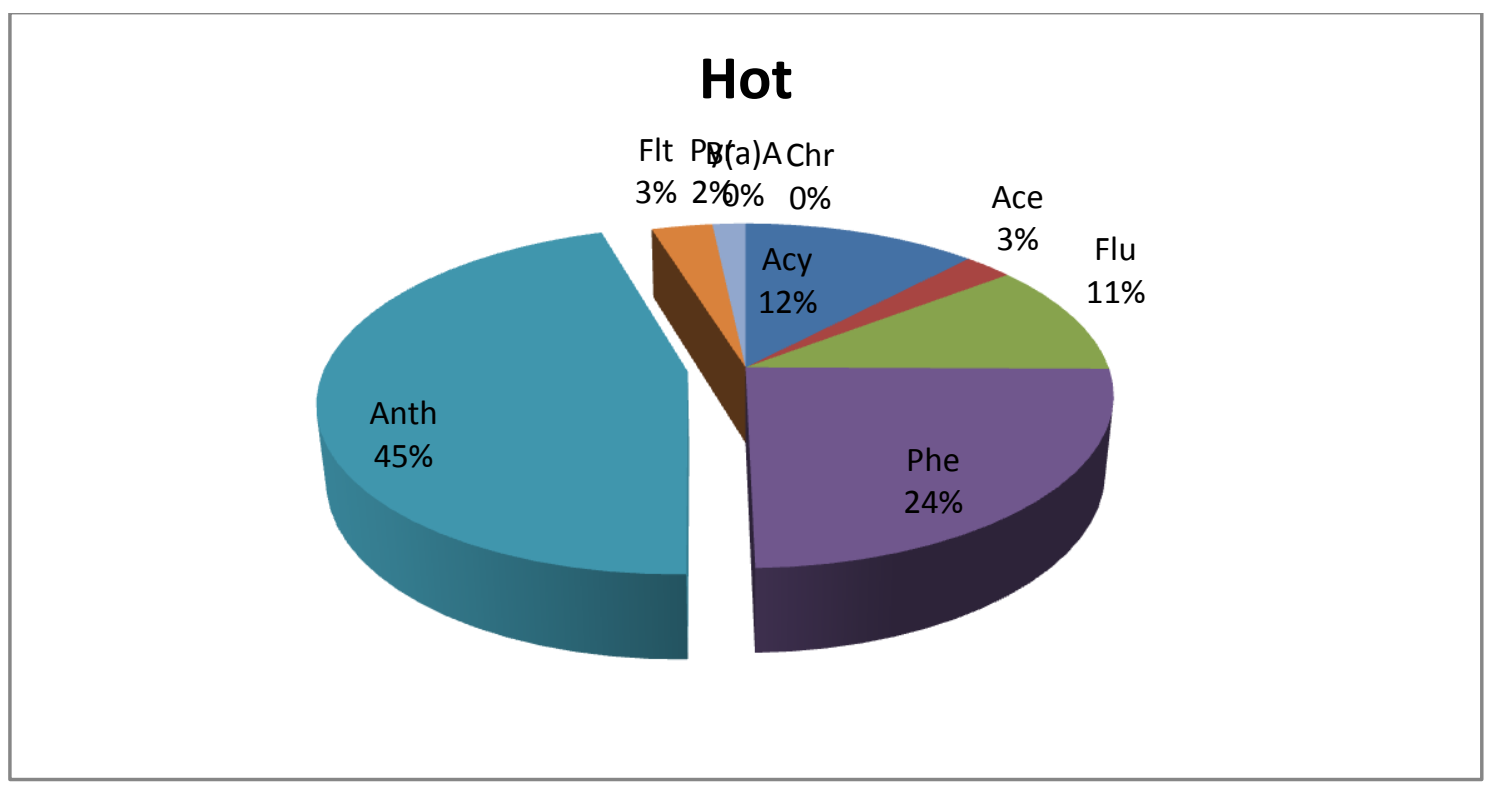

Figure 3:-Percent of detectedBaPeq PAHs in hot smoked catfish (fillets.

\section{Conclusion:-}

The obtained results in our study showed that the cold and hot smoked catfish fish (Clariasgariepinus) fillets contained 7 compounds low molecular weight of PAHs; acenaphthylene, acenaphthene, fluorene, phenanthrene, anthracene, fluoranthene and pyrene. Benzo(a)anthracene and chrysenethat high molecular weight were detected only in cold smoked samples. A significant $(\mathrm{P} \leq 0.05)$ higher concentrations of detected PAHs compoundswere recorded of cold smoked samples than hot smoked.Benzo[a]pyrene(BaP) compound that considered as indicators for carcinogenic PAHs was not detected in both cold and hot smoked catfish fillets. PAH4 (benzo(a)pyrene, benz(a)anthracene, benzo (b)fluoranthene and chrysene) ; only benz(a)anthracene and chrysene were found in cold smoked samples $(10.7 \mu \mathrm{g} / \mathrm{kg})$ below than the maximum tolerable risk limits $(12 \mu \mathrm{g} / \mathrm{kg})$. Sum of toxic equivalency BaPeq (TEQ) was recorded a significant higher $(\mathrm{P} \leq 0.05)$ value for cold smoked catfish fillets than hot smoked fillets. Therefore, Smoking was found to generally increase the PAHs levels with the various smoking methods contributing PAHs to varying degrees. This study showed that hot smoking method could be safer and deemed fit 
for human consumption than cold smokingalthough, the results reveal that the fish samples smoked by two different methods do not constitute a health risk, as the benzo (a) pyrene are not detected.

\section{References:-}

1. Abd El- Mageed, S. A. (1994): Chemical and technological studies on fish smoking. M. Sc., Thesis, Fac. of agric., Al-Azhar Univ.

2. Andrzej, S. and Sikorski, Z. E. (2005): Polycyclic aromatic hydrocarbons in smoked fish - a critical review. Food Chemistry 91, 303-311.

3. Basak, S.; Şengör, G. F. and Karakoç, F. T. (2010): The Detection of Potential Carcinogenic PAH Using HPLC Procedure in Two Different Smoked Fish, Case Study: Istanbul/Turkey. Turk. J. Fish. Aquat. Sci. 10: 351-355.

4. EFSA (2008): European Food Safety Agency. Polycyclic aromatic hydrocarbons in food.The EFSA Journal, $724,1 \mathrm{e} 114$.

5. Garcia-Falcon, M. S and Simal-Gandara, J. (2005): Polycyclic aromatic hydrocarbons in smoke from different woods and their transfer during traditional smoking into chorizo sausages with collagen and tripe casings. Food Addit.Contam, 22: 1-8.

6. Gómez-Estaca, J.; Gómez-Guillén, M. C.; Montero, P.; Sopelana, P.; Guillén, M. D. (2011): Oxidative stability, volatile components and polycyclic aromatic hydrocarbons of cold-smoked sardine (Sardinapilchardus) and dolphin fish (Coryphaenahippurus). LWT - Food Sci. Technol., 44: 1517-1524.

7. Gómez-Guillén, M. C.; Gómez-Estaca, J.; Giménez, B. and Montero, P. (2009): Alternative fish species for cold-smoking process. Int. J. Food Sci. Technol., 44: 1525-1535.

8. Ishizaki, A.; Saitoa, K.; Haniokab, N.; Narimatsub, S. and Kataokaa, H. (2010): Determination of polycyclic aromatic hydrocarbons in food samples by automated on-line in-tube solid-phase microextraction coupled with high-performance liquid chromatography-fluorescence detection. J. Chromatogra., 1217: 5555-5563.

9. Khorshid, M.; Souaya, E. R.; Hamzawy, A. H. and Mohammed, M. N. ( 2015): QuEChERS Method Followed by Solid Phase Extraction Method for Gas Chromatographic Mass Spectrometric Determination of Polycyclic Aromatic Hydrocarbons in Fish International Journal of Analytical Chemistry Article ID 352610.

10. Mihalca, G. L.; Tiţa, O.; Mihaela, T. and Mihalca, A. (2011): Polycyclic aromatic hydrocarbons (PAHs) in smoked fish from three smoke-houses in Brasov County. Journal of Agroalimentary Processes and Technologies 17(4), 392-397.

11. Neff, J. M. (1985): Polycyclic Aromatic Hydrocarbons. IN Rand GM, Petrocelly SR (Eds.) Fundamentals of Aquatic Toxicology.Taylor and Francis.

12. Nisbet, I. C. T. and Lagoy, P. K. (1992): Toxic Equivalency Factors (TEFs) for Polycyclic Aromatic Hydrocarbons (PAHs) regulatory toxicology and pharmacology 16,290-3t.

13. OJEU (Official Journal of the European Union) (2006): EU Commission Regulation (EC) No 1881/2006 of December 192006 setting maximum levels for certain contaminants in foodstuffs. 20.12.2006, L364/5e23.

14. OJEU (Official Journal of the European Union) (2011): commission regulation (EU) No 835/2011 of 19 August 2011. amending Regulation (EC) No $1881 / 2006$ as regards maximum levels for polycyclic aromatic hydrocarbons in foodstuffs 20.8.2011 L 215/4.

15. Olabemiwo OM, Alade AO, Tella AC, Adediran GO (2011). Assassment of polycyclic aromatic hydrocarbons content in smoked C. gariepinnus and T. guineensis fish species available in Western Nigeria. Int. J. Basic Appl. Sci. 11(2):135-150.

16. Ongwech, A.; William, G. N.; Mbabazi, J. K. and Masette, M. (2013): Polycyclic aromatic hydrocarbons in smoked Latesniloticus from selected markets, Gulu District, Uganda. African Journal of Pure and Applied ChemistryVol. 7(4), pp.164-172.

17. Rey-Salgueiro, L.; Garcia-Falcón, M. S.; Soto-Gonzalez, B. and Simal-Gándara, J. (2009): Occurrence of polycyclic aromatic hydrocarbons and their hydroxylated metabolites in infant foods. Food Chem., 115: 814819.

18. Silva, B. O., Adetunde, O. T., Oluseyi, T. O., Olayinka, K. O., Alo, B. I. (2011): Effects of the methods of smoking on the levels of polycyclic aromatic hydrocarbons (PAHs) in some locally consumed fishes in Nigeria. African Journal of Food Science Vol. 5(7), pp. 384-391.

19. Simko P (2002): Determination of polycyclic aromatic hydrocarbons in smoked meat products and smoke flavouring food additives. Journal of Chromatography B: Analytical Technologies in the Biomedical and Life Sciences 770(1-2):3-18.

20. SPSS (1991): Statistical Package for Social Science.

21. Stołyhwo, A. and Sikorski, Z. (2005): Polycyclic aromatic hydrocarbons in smoked fish - a critical review. Food Chem., 91: 303-311. 
22. US EPA (US Environmental Protection Agency) (1993): Provisional guidance for the quantitative risk assessment of polycyclic aromatic hydrocarbons. US environmental protection agency report (No. EPA/600/R-93/089): US Environmental Protection Agency.

23. US EPA (US Environmental Protection Agency) (1994): Federal Register, 59 FR 1788.

24. US EPA (US Environmental Protection Agency) (2002): Polycyclic organic matter. Environmental Protection Agency, Washington, DC, Available from: bhttp:// www. epa.gov/ttn/atw/hlthef/polycycl.html.

25. Wenzl, T.; Simon, R.; Anklam, E. and Kleiner, J. (2006): Analytical methods for polycyclic aromatic hydrocarbons (PAHs) in food and the environment needed for new food legislation in the European Union, TrAC-Trends in Analytical Chemistry,vol.25, no. 7, pp. 716-725.

26. WHO/IARC (2012): World Health Organization/ International Agency for Research on Cancer. IARC Monographs on the evaluation of carcinogenic risks to humans, Vol. $100 \mathrm{~F}$. International Agency for Research on Cancer, Lyon.

27. Zelinkova, Z. and Wenz, T. (2015): The Occurrence of 16 EPA PAHs in Food - A Review. Polycyclic Aromatic Compounds, 35:248-284. 